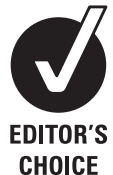

CHOICE

\section{See Editorial, p 237}

${ }^{1}$ Department of Occupational Medicine, Buddhist Tzu Chi General Hospital, Hualien, Taiwan

${ }^{2}$ School of Medicine, Tzu Chi University, Hualien, Taiwan ${ }^{3}$ Institute of Occupational Medicine and Industrial Hygiene, National Taiwan University College of Public Health, Taipei, Taiwan

${ }^{4}$ Department of Internal Medicine, National Taiwan University Hospital, Taipei, Taiwan

${ }^{5}$ Department of Environmental and Occupational Medicine, National Taiwan University Hospital, Taipei, Taiwan ${ }^{6}$ Public Health Bureau, Miaoli, Taiwan

\section{Correspondence to} Dr Pau-Chung Chen, Institute of Occupational Medicine and Industrial Hygiene, National Taiwan University College of Public Health, No. 17 Xuzhou Road, Taipei 100, Taiwan; pchen@ntu.edu.tw

Accepted 3 September 2010 Published Online First 8 October 2010

\title{
Occupational kidney disease among Chinese herbalists exposed to herbs containing aristolochic acids
}

\author{
Hsiao-Yu Yang, ${ }^{1,2,3}$ Jung-Der Wang, ${ }^{3,4,5}$ Tsai-Chang Lo, ${ }^{6}$ Pau-Chung Chen ${ }^{3,5}$
}

\begin{abstract}
Objective Many Chinese herbs contain aristolochic acids (ALAs) which are nephrotoxic and carcinogenic. The objective of this study was to identify whether exposure to herbs containing ALAs increased the risk of kidney disease among Chinese herbalists.

Methods A nested case-control study was carried out on 6538 Chinese herbalists registered between 1985 and 1998. All incident cases of chronic renal failure reported to the Database of Catastrophic IIIness of the National Health Insurance Bureau between 1995 and 2000 were defined as the case group. Up to four controls without renal failure were randomly matched to each case by sex and year of birth. A structured questionnaire survey was administered between November and December 2002. The Mantel-Haenszel method and conditional logistic regression were used to estimate the risks.
\end{abstract}

Results 40 cases and 98 matched controls were included in the final analysis. After adjusting for age, frequent analgesic use, and habitual consumption of alcohol, fermented or smoked food, we found manufacturing and selling Chinese herbal medicine (OR $3.43,95 \% \mathrm{Cl} 1.16$ to 10.19 ), processing, selling or dispensing herbal medicines containing Fangji (OR 4.17, $95 \% \mathrm{Cl} 1.36$ to 12.81), living in the workplace (OR 3.14, $95 \% \mathrm{Cl} 1.11$ to 8.84 ) and a history of taking of herbal medicines containing Fangji (frequently or occasionally) (OR 5.42, 95\% Cl 1.18 to 24.96) were significantly associated with renal failure.

Conclusion Occupational exposure to and consumption of herbs containing ALAs increases the risk of renal failure in Chinese herbalists.

\section{INTRODUCTION}

Herbal medicine has been used extensively worldwide throughout human history, in large part because herbal drugs are believed to be harmless. In 1993, Vanherweghem et al first reported that many young women who took the Chinese herb Fangji, which contains aristolochic acids (ALAs), had developed renal failure and urothelial carcinoma. ALAs are known to be strongly nephrotoxic and carcinogenic. $^{2-4}$ Many patients with kidney diseases or urothelial carcinoma related to the use of Chinese herbs containing ALAs have been reported in recent years, especially in Asia and

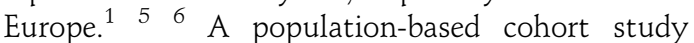
investigating the health risks of workers exposed to Chinese herbs was conducted among certified physicians of traditional Chinese medicine (TCM) in Taiwan between 1985 and 2005 and found that

\section{What this paper adds}

Many Chinese herbs contain aristolochic acids (ALAs) which are nephrotoxic and carcinogenic.

- The occupational health risks among workers who handle herbs containing ALAs in an occupational setting remain unknown.

- This study shows that herbalists have an increased risk of chronic renal failure if they process, sell or dispense Fangii (which contains ALAs).

- Workers who process herbs containing ALAs and then develop kidney diseases could be considered to have an occupational disease.

- The government should provide educational programs on the risk of ALAs and arrange medical follow-up for herbalists.

these physicians had an increased risk of certain cancers. ${ }^{7}$ However, Chinese herbalists have higher exposure to herbs than TCM physicians because they process and have direct contact with the herbs; nevertheless, research on the occupational risks faced by herbalists is still scanty. Working as a Chinese herbalist is a traditional occupation in Chinese society ${ }^{8}$ and TCM has been practised in Taiwan since the 16th century. Practitioners inherit their knowledge, which is passed down from parents to their descendants, or learn through apprenticeships. ${ }^{9}$ Herbalists are a special occupational group as many have high exposure to ALAs and increased risk of kidney disease. Our previous studies on a national cohort of Chinese herbalists showed that they had higher mortality from urological cancer (standardised mortality rate (SMR) 3.10, 95\% CI 1.41 to 5.87) and chronic renal failure (SMR 2.40, 95\% CI 1.40 to 3.84$),{ }^{10}$ and a higher incidence of urological cancer (standardised incidence rate (SIR) 3.51, 95\% CI 2.37 to 5.01). ${ }^{11}$

However, these studies used length of employment as a surrogate for the degree of exposure to herbs and therefore more methodologically stringent epidemiological studies with information on the occupational, environmental, lifestyle and past medical history of these Chinese herbalists are needed to verify the association.

Based on walk-through observations and interview surveys, we proposed potential routes of ALA exposure. One route is by ingestion. In the early years of their apprenticeship, herbalists process raw 
herbs by cutting, refining, grinding, selling and solar drying. These processes produce airborne dust which can be deposited in the mouth and swallowed. The second route is by eating contaminated foods. Because traditional herbal stores are usually small family businesses, many of the manufacturing procedures are performed in the store's backyard in a common workplace/ dining area. Food could therefore be contaminated by herbal dust. The third route is that herbalists are more likely to take herbal drugs because they are accessible and are therefore likely to consume herbs including those containing ALAs, especially Fangji, the most frequently misused herb.

The objective of this study was to identify whether occupational exposure to herbs containing ALAs increased the risk of kidney disease among Chinese herbalists.

\section{MATERIALS AND METHODS}

To analyse the occupational risk of renal failure among Chinese herbalists, a nested case-control study using a national cohort of all Chinese herbalists in Taiwan was designed. The occupational cohort consisted of all herbalists who were registered with the Chinese Herbalist Union between 1 January 1985 (when the union was established) and 31 December $1998 .^{10}$ Through linkage to the Database of Catastrophic Illness of the National Health Insurance Bureau, which was set up in 1995 and covers $97 \%$ of the Taiwanese population, ${ }^{12}$ we followed the development of chronic renal failure in this cohort between 1995 and 2000. All incident cases of chronic renal failure (ICD-9-CM 585) reported to the registry were defined as the case group. The criterion of chronic renal failure was defined as irreversible renal function impairment with $\mathrm{Ccr}<5 \mathrm{ml} / \mathrm{min}$ or serum creatinine level $\geq 10.0 \mathrm{mg} / \mathrm{dl}$ requiring regular haemodialysis. The diagnosis was certified by a nephrologist and forwarded to the National Health Insurance Bureau. Up to four controls without chronic renal failure from among this cohort were individually matched to each case by sex and year ( \pm 5 years) of birth in a randomised manner.

A structured questionnaire was administered by trained interviewers between November and December 2002. The questionnaire sought information on: (1) demographic data (including age, sex, marital status and educational level); (2) whether an individual had a personal or family history (in a firstdegree relative) of urinary stones, bladder cancer, kidney cancer or uraemia; (3) frequency of analgesic use (more than once per week); (4) consumption of herbal medicines containing Fangii; (5) occupational history (including the age they started working with Chinese herbs, the number of years manufacturing or selling Chinese herbal medicine, average daily work hours, processing procedures carried out, and whether they had processed, sold or dispensed herbal medicines containing Fangji at work); (6) lifestyle factors (including smoking habits, alcohol consumption, coffee and tea consumption (ie, whether they consumed these beverages on more than 3 days per week for more than 6 months), and consumption of fermented food, smoked food or artificial sweeteners more than once per week; (7) their history of potential environmental exposure to toxicants (including whether they had been exposed to organic solvents, paints or pesticides (for a period lasting longer than 6 months), their history of drinking well water from deep wells $>60 \mathrm{~m}$ in depth), and whether they lived in their workplaces. Data were analysed using Stata 10.0. To analyse the data stratified by matched pairs, we used the Mantel-Haenszel method and calculated the crude ORs for possible explanatory variables (using the mhodds function in Stata). The important explanatory variables found in the univariable analysis were then included in multivariate conditional logistic regression to adjust the confounding (the clogit function in Stata). For all of the analyses, two-tailed $p$ values $<0.05$ were considered statistically significant. The study was approved by the Ethics Committee of the National Taiwan University College of Public Health.

\section{RESULTS}

Fifty-five incident cases of chronic renal failure (uraemia) were accrued during the observation period among a cohort of 6538 Chinese herbalists, and were matched with 194 individuals without uraemia. After excluding 15 cases and 96 controls who refused to complete the questionnaire, our study ultimately consisted of 40 cases (response rate $73.7 \%$ ) and 98 controls (response rate $50.5 \%$ ) for analysis (figure 1). There were no significant differences in the distributions of age, sex, education, type of herbal store, years spent manufacturing or selling herbal medicine, procedures carried out or daily hours worked between the case and control groups.

Most herbalists were born before 1955 and had only completed elementary school education. The majority worked in traditional herbal stores and participated in most of the steps processing herbal medicines. Among the cases, the median age at diagnosis of chronic renal failure was 50.8 years, the average years they had spent manufacturing or selling Chinese herbal medicines was 19.1 (SD 15.0 years), and the number of hours they spent at work each day was 7.1 (SD 4.5) (table 1).

There was a strong association between the development of chronic renal failure and occupational exposure to Fangji. From the univariable analysis with the Mantel-Haenszel procedure, we found that participating in the manufacturing and selling of Chinese herbal medicine, the processing, selling or dispensing of herbal medicine containing Fangji, frequent use of analgesics (ie, more than once per week) and a history of taking herbal medicines containing Fangji were all significantly associated with the development of renal failure. Otherwise, the ORs of habitual

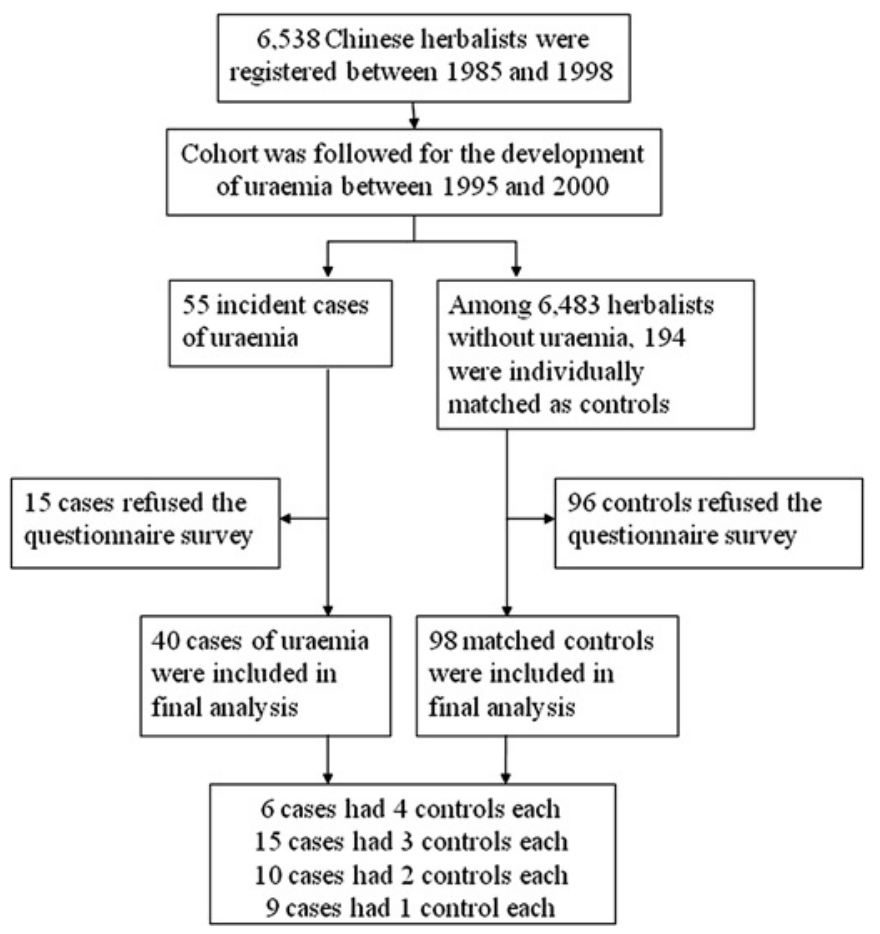

Figure 1 Flow diagram showing the selection of cases and controls. 
Table 1 Characteristics of the case and control groups

\begin{tabular}{|c|c|c|}
\hline & $\begin{array}{l}\text { Cases } \\
(n=40)\end{array}$ & $\begin{array}{l}\text { Controls } \\
(n=98)\end{array}$ \\
\hline \multicolumn{3}{|l|}{ Birth year $(\%)$} \\
\hline 1935 or before & $4(10.0)$ & $24(24.5)$ \\
\hline $1936-1945$ & $17(42.5)$ & $33(33.7)$ \\
\hline $1946-1955$ & $13(32.5)$ & $32(32.7)$ \\
\hline 1956 or after & $6(15.0)$ & $9(9.2)$ \\
\hline \multicolumn{3}{|l|}{$\mathrm{Age}^{*}$} \\
\hline Median & 50.8 & 52.9 \\
\hline$<45$ years $(\%)$ & $11(27.5)$ & $19(19.4)$ \\
\hline $45-54$ years $(\%)$ & $18(45.0)$ & $37(37.8)$ \\
\hline $55-64$ years $(\%)$ & $11(27.5)$ & $32(32.7)$ \\
\hline$\geq 65$ years $(\%)$ & $0(0)$ & $10(10.2)$ \\
\hline Number of females $(\%)$ & $28(70.0)$ & $65(66.3)$ \\
\hline \multicolumn{3}{|l|}{ Educational level } \\
\hline Illiterate (\%) & $2(5.0)$ & $7(7.1)$ \\
\hline Elementary (\%) & $19(47.5)$ & $48(49.0)$ \\
\hline Junior high (\%) & $9(22.5)$ & $20(20.4)$ \\
\hline Senior high (\%) & $6(15.0)$ & $17(17.3)$ \\
\hline College (\%) & $3(7.5)$ & $5(5.1)$ \\
\hline \multicolumn{3}{|l|}{ Lifestyle factors } \\
\hline Smoking habit ( $>3$ days/week for $>6$ months) (\%) & $8(20)$ & $17(17.3)$ \\
\hline $\begin{array}{l}\text { Habitual alcohol consumption (> once per week for } \\
>6 \text { months) (\%) }\end{array}$ & $7(17.5)$ & $12(12.2)$ \\
\hline $\begin{array}{l}\text { Habitual tea consumption ( }>3 \text { days/week } \\
\text { for }>6 \text { months) }(\%)\end{array}$ & $14(35.0)$ & $37(37.8)$ \\
\hline $\begin{array}{l}\text { Habitual consumption of fermented food } \\
\text { ( }>\text { once per week) (\%) }\end{array}$ & $7(17.5)$ & $8(8.2)$ \\
\hline $\begin{array}{l}\text { Habitual consumption of smoked food } \\
\text { ( }>\text { once per week) (\%) }\end{array}$ & $2(5.0)$ & $2(2.0)$ \\
\hline History of drinking deep well water (\%) & $8(21.1)$ & $19(20.9)$ \\
\hline \multicolumn{3}{|l|}{ Type of herbs sold in store } \\
\hline Traditional herbal medicine (\%) & $11(27.5)$ & $28(28.6)$ \\
\hline Patent Chinese medicine (\%) & $2(5.0)$ & $5(5.1)$ \\
\hline Both (\%) & $20(50.0)$ & $32(32.7)$ \\
\hline $\begin{array}{l}\text { Number of years spent manufacturing or } \\
\text { selling Chinese herbal medicine (SD) }\end{array}$ & $19.1(15.0)$ & $21.0(19.8)$ \\
\hline Daily work hours (SD) & $7.1(4.5)$ & $6.0(5.0)$ \\
\hline \multicolumn{3}{|l|}{ Procedures in which they participated } \\
\hline Cutting (\%) & $15(37.5)$ & $40(40.8)$ \\
\hline Refining (\%) & $10(25.0)$ & 37 (37.8) \\
\hline Grinding $(\%)$ & $15(37.5)$ & $39(39.8)$ \\
\hline Selling $(\%)$ & $25(62.5)$ & $44(44.9)$ \\
\hline solar drying (\%) & $13(32.5)$ & $35(35.7)$ \\
\hline Prescribing patent Chinese medicine (\%) & $8(20.0)$ & $22(22.4)$ \\
\hline
\end{tabular}

${ }^{*}$ Age at diagnosis of chronic renal failure of cases and the age of the matched controls at the time of the survey.

consumption of alcohol (OR 2.30, 95\% CI 0.65 to 8.20), habitual consumption of fermented food (OR $2.93,95 \%$ CI 0.86 to 10.03 ) and habitual consumption of smoked food (OR 4.0, 95\% CI 0.26 to 61.22) were high although not statistically significantly. After adjusting for age, frequent use of analgesics, habitual consumption of alcohol, habitual consumption of fermented food, and habitual consumption of smoked food, the final model revealed that actual participation in the manufacturing and selling of Chinese herbal medicines, processing, selling, or dispensing herbal medicines containing Fangji, living in the workplace and a history of taking herbal medicines containing Fangji (frequently or occasionally) were significantly associated with the development of renal failure (table 2).

\section{DISCUSSION}

The role of ALAs in the pathogenesis of kidney disease has attracted much interest in recent years, but few studies have focused on the health risks for workers who are chronically exposed to these agents. Consistent with our observation that Chinese herbalists have a higher probability of exposure to herbs containing ALAs, this study provides evidence that herbalists have an increased risk of developing renal disease and/or renal failure because of their occupation.

We identified Chinese herbalists who had developed renal disease through linkage with the Database of the National Health Insurance Bureau, which covers most of the Taiwanese population. Any selection bias introduced by loss to follow-up was therefore minimised. As nephrologists use identical criteria when diagnosing chronic renal failure, the potential for misclassification bias was also limited. All cases began working in Chinese herbal medicine before they developed chronic renal failure, and a temporal relationship was thus established. Some workers in Taiwan may be insured through unions although they do not actually work in the type of job represented by the particular union. However, this study obtained information through face-to-face interviews and asked respondents whether they participated in the manufacturing and selling of herbal medicine and so information regarding exposure to Fangji was verified by trained interviewers. Moreover, the average number of years spent manufacturing or selling Chinese herbal medicines was 19 years in cases and 21 in controls. As Fangji is a common herbal drug, herbalists in both groups would know if they had ever used it. Information bias was therefore minimised, allowing us to obtain a more precise estimation of risk. However, this case-control study might be subject to recall bias as the response rate was lower in the control group and so the ORs might be over-estimated and should be interpreted carefully.

ALAs are nephrotoxic agents that can cause progressive interstitial fibrosis, proximal tubular atrophy and glomerular sclerosis. ${ }^{13} 14$ ALAs are derived from extracts of plants of the Aristolochia, Bragantia and Asarum species and are a common constituent of many Chinese herbs, such as Madouling (Aristolochiae debilis), Tianxianteng (Aristolochiae contorta), Oingmuxiang (Aristolochiae cucurbitifolia), Guang Fangji (Aristolochiae fangii), Guanmutong (Aristolochiae manshuriensis) and Xixin (Radix et Rhizoma asari). ${ }^{45-18}$ Due to the complex nomenclature system for Chinese herbs, ${ }^{15}$ Fangji is generally misused. Thousands of years ago in China, Fangji referred to Han Fangji (Stephania tetrandra) which does not contain ALAs. But hundreds of years ago, it gradually began to refer to Guang Fangji (A fangii) which does contain ALAs and was exported to Taiwan. ${ }^{18} 19$ Therefore, individuals who consume Fangji may be at risk of ALA exposure. Our other retrospective follow-up study using a systematic random sample of 200000 people from the National Health Insurance Bureau reimbursement database of Taiwan for 1997-2002, found that a cumulative prescribed dose of more than $60 \mathrm{~g}$ Fangii was associated with an increased risk of developing chronic kidney disease. ${ }^{20}$ This study of Chinese herbalists consistently finds that exposure to Fangji increases the risk of kidney disease. Similar to the situation in the Belgian and Balkan epidemics, ${ }^{21-26}$ we propose that the herbalists were orally exposed to ALAs when they swallowed herbal dust, ate contaminated food and took herbs containing ALAs. In previous years, herbalists usually carried out all procedures involved in producing herbal medicines and so the most dangerous step in terms of ALA exposure cannot be identified. More in-depth exposure assessments, including air sampling of the dust produced in each step, are suggested for further research.

This study has some potential limitations. Although the association between exposure to ALAs and chronic renal failure was strong, the small sample size means the findings of this 
Table 2 Association between exposure to Chinese herbs and the development of uraemia

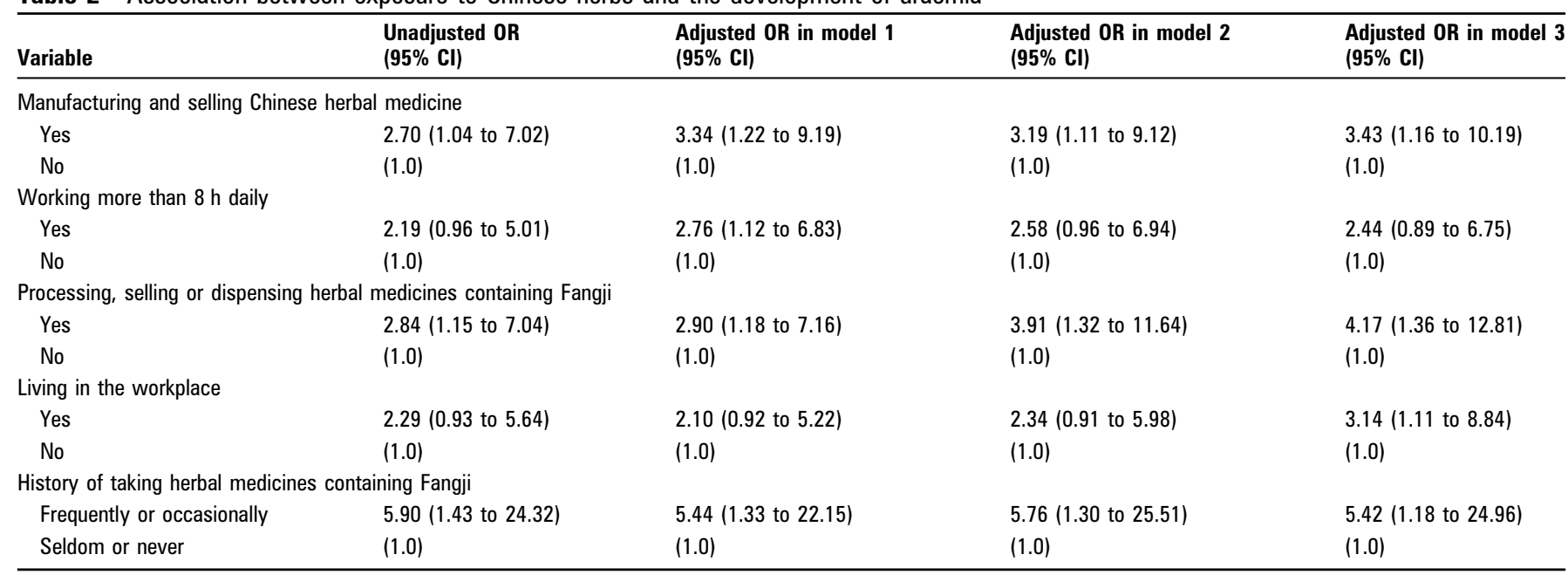

The unadjusted OR is estimated using the Mantel-Haenszel procedure and the adjusted OR is estimated using conditional logistic regression models.

Model 1: adjusted for age; model 2: adjusted for age and frequent use of analgesics; model 3: adjusted for age, frequent use of analgesics, habitual consumption of alcohol, habitual consumption of fermented food, and habitual consumption of smoked food.

study should be confirmed or validated by other larger studies. We also consider alternative explanations. First, the long-term use of analgesics is an important risk factor for chronic kidney disease. $^{27}$ Our study found that the frequent use of analgesics was an important risk factor for renal failure (OR 8.22, 95\% CI 1.97 to 34.38$)$, but after we adjusted for this factor, we found that participation in the processing, selling or dispensing of herbal medicines containing Fangji (OR 3.82, 95\% CI 1.29 to 11.28) and a history of taking herbal medicines containing Fangji (frequently or occasionally) (OR 5.68, 95\% CI 1.28 to 25.25 ) were still significantly associated with an increased risk. Second, arsenic in drinking water was reported to increase the risk of kidney disease, ${ }^{28}$ and arsenic contamination in deep well water has been found in some areas of Taiwan. ${ }^{29}{ }^{30}$ In this study, the proportions of individuals who had consumed deep well water were similar in the case and control groups $(21.1 \%$ vs $20.9 \%$, respectively) and so drinking arsenic-contaminated water was probably not related to the increased risk. In Taiwan, raw Chinese herbs are mainly imported from mainland China, and many were reported to be contaminated with heavy metals, including arsenic, lead and cadmium. ${ }^{51-34}$ We suspected that heavy metal contamination might also play a role in the increased risk of kidney disease. If the probability of exposure to herbs containing heavy metals was similar in both groups, the confounding from heavy metals would not bias our estimation of the risk of exposure to Fangji. We suggest heavy metals serum levels in herbalists should be determined in future studies.

Because the association between the processing, selling or dispensing of herbal medicines containing Fangji and the development of chronic renal failure was strong, we suggest that kidney disease among Chinese herbalists exposed to Fangji at work is likely to be an occupational disease. The significantly increased risk of renal failure observed in herbalists also means that regular medical follow-up is urgently required to ensure that these herbalists remain in good health. As our study also showed that living in the workplace was significantly associated with the development of chronic renal failure, we suggest that family members should also be screened for kidney disease.

In 2003, the Committee on Chinese Medicine and Pharmacy of the Department of Health in Taiwan prohibited the use of herbal drugs (including Madouling, Tianxianteng, Oingmuxiang, Guang Fangji and Guanmutong) containing ALAs. But based on our walk-though surveys, we find that misuse of Fangji (Guang Fangji) is still common. We therefore suggest that the law is enforced and the import or use of herbs containing ALAs is strictly forbidden.

Chinese herbal shops are becoming more popular in other countries, but formal training and management systems may be lacking. Therefore, we suggest that governments monitor the safety of herbal medicines and educate herbalists about ALAcontaining herbs and their health risks. In Chinese medicine, Fangji is indicated for diuretic and laxative use and so might also be used for slimming. We recommend that physicians be alert for patients with both renal disease and chronic use of herbal products for oedema, constipation or losing weight; such patients should also be warned about the risks and their renal health monitored. In addition to nephrotoxicity, other studies have shown that chronic use of Chinese herbal drugs carries some risks of hepatotoxicity and congenital malformations. ${ }^{35} 36$ Chinese herbs are commonly used for pregnant women, children, cancer patients, the elderly and patients with chronic disease $e^{37-39}$ because it is believed that herbs are usually harmless. We suggest that the public should also be educated about their potential adverse effects.

\section{Conclusion}

Occupational exposure to and the consumption of herbs containing ALAs increase the risk of kidney disease among Chinese herbalists.

\section{Competing interests None.}

Ethics approval This study was conducted with the approval of the Ethics Committee of the National Taiwan University College of Public Health.

Provenance and peer review Not commissioned; externally peer reviewed.

\section{REFERENCES}

1. Vanherweghem JL, Depierreux M, Tielemans $\mathrm{C}$, et al. Rapidly progressive interstitial renal fibrosis in young women: association with slimming regimen including Chinese herbs. Lancet 1993;341:387-91.

2. Cosyns JP. Aristolochic acid and 'Chinese herbs nephropathy': a review of the evidence to date. Drug Saf 2003;26:33-48.

3. Debelle FD, Vanherweghem JL, Nortier JL. Aristolochic acid nephropathy: a worldwide problem. Kidney Int 2008;74:158-69.

4. International Agency for Research on Cancer. IARC monographs on the evaluation of carcinogenic risks to humans volume 82 (2002): some traditional herbal medicines, some mycotoxins, naphthalene and styrene. http://monographs.iarc.fr/ ENG/Monographs/vol82/index.php (accessed Sep 27, 2010). 
5. Au AM, Ko R, Boo FO, et al. Screening methods for drugs and heavy metals in Chinese patent medicines. Bull Environ Contam Toxicol 2000;65:112-19.

6. Li XB, Xing NZ, Wang Y, et al. Transitional cell carcinoma in renal transplant recipients: a single center experience. Int J Urol 2008;15:53-7.

7. Liu SH, Liu YF, Liou SH, et al. Mortality and cancer incidence among physicians of traditional Chinese medicine: a 20-year national follow-up study. Occup Environ Med 2010;67:166-9.

8. Chang HC, Tsai KH. Characteristics of Chinese herbalists in Taiwan (in Chinese). Disquisitions on the Past and Present 2004:11:96-114.

9. Chi C, Lee JL, Lai JS, et al. The practice of Chinese medicine in Taiwan. Soc Sci Med 1996;43:1329-48.

10. Yang HY, Wang JD, Lo TC, et al. Increased mortality risk for cancers of the kidney and other urinary organs among Chinese herbalists. J Epidemiol 2009;19:17-23.

11. Yang HY, Wang JD, Lo TC, et al. Increased risks of upper tract urothelial carcinoma in male and female Chinese herbalists. J Formos Med Assoc In Press.

12. Lu JF, Hsiao WC. Does universal health insurance make health care unaffordable? Lessons from Taiwan. Health Aff (Millwood) 2003;22:77-88.

13. Depierreux M, Van Damme B, Vanden Houte K, et al. Pathologic aspects of a newly described nephropathy related to the prolonged use of Chinese herbs. Am J Kidney Dis 1994:24:172-80.

14. Nortier JL, Vanherweghem JL. Renal interstitial fibrosis and urothelial carcinoma associated with the use of a Chinese herb (Aristolochia fangchi). Toxicology 2002;181-182:577-80.

15. Wu KM, Farrelly JG, Upton R, et al. Complexities of the herbal nomenclature system in traditional Chinese medicine (TCM): lessons learned from the misuse of Aristolochia-related species and the importance of the pharmaceutical name during botanical drug product development. Phytomedicine 2007;14:273-9.

16. Jong TT, Lee MR, Hsiao SS, et al. Analysis of aristolochic acid in nine sources of Xixin, a traditional Chinese medicine, by liquid chromatography/atmospheric pressure chemical ionization/tandem mass spectrometry. J Pharm Biomed Anal 2003;33:831-7.

17. Drew AK, Whyte IM, Bensoussan A, et al. Chinese herbal medicine toxicology database: monograph on Herba Asari, "xi xin". J Toxicol Clin Toxicol 2002; 40:169-72

18. Cheung TP, Xue C, Leung $\mathrm{K}$, et al. Aristolochic acids detected in some raw Chinese medicinal herbs and manufactured herbal products-a consequence of inappropriate nomenclature and imprecise labelling? Clin Toxicol (Phila) 2006;44:371-8.

19. Tung CF, Ho YL, Tsai HY, et al. Studies on the commonly misused and adulterated Chinese crude drug species in Taiwan (In Chinese). Chin Med Coll J 1999:8:35-46.

20. Lai MN, Lai JN, Chen PC, et al. Increased risks of chronic kidney disease associated with prescribed Chinese herbal products suspected to contain aristolochic acid. Nephrology (Carlton) 2009;14:227-34.

21. Lemy A, Wissing KM, Rorive $\mathrm{S}$, et al. Late onset of bladder urothelial carcinoma after kidney transplantation for end-stage aristolochic acid nephropathy: a case series with 15-year follow-up. Am J Kidney Dis 2008:51:471-7.
22. Cosyns JP, Jadoul M, Squifflet JP, et al. Urothelial lesions in Chinese-herb nephropathy. Am J Kidney Dis 1999;33:1011-17.

23. Chernozemsky IN, Stoyanov IS, Petkova-Bocharova TK, et al. Geographic correlation between the occurrence of endemic nephropathy and urinary tract tumours in vratza district, Bulgaria. Int J Cancer 1977;19:1-11.

24. Dragicevic D, Djokic M, Pekmezovic T, et al. Survival of patients with transitional cell carcinoma of the ureter and renal pelvis in Balkan endemic nephropathy and nonendemic areas of Serbia. BJU Int 2007;99:1357-62.

25. Djokic M, Hadzi-Djokic J, Nikolic J, et al. Comparison of upper urinary tract tumors in the region of Balkan nephropathy with those of other regions of Yugoslavia. Prog Urol 1999;9:61-8.

26. Miletić-Medved M, Domijan A-M, Peraica M. Recent data on endemic nephropathy and related urothelial tumors in Croatia. Wien Klin Wochenschr 2005;117:604-9.

27. Eknoyan G. Current status of chronic analgesic and nonsteroidal anti-inflammatory drug nephropathy. Curr Opin Nephrol Hypertens 1994:3:182-8.

28. Meliker JR, Wahl RL, Cameron LL, et al. Arsenic in drinking water and cerebrovascular disease, diabetes mellitus, and kidney disease in Michigan: a standardized mortality ratio analysis. Environ Health 2007;6:4.

29. Chiou HY, Chiou ST, Hsu YH, et al. Incidence of transitional cell carcinoma and arsenic in drinking water: a follow-up study of 8,102 residents in an arseniasisendemic area in northeastern Taiwan. Am J Epidemiol 2001;153:411-18.

30. Chen CJ, Hsu LI, Wang CH, et al. Biomarkers of exposure, effect, and susceptibility of arsenic-induced health hazards in Taiwan. Toxicol Appl Pharmacol 2005;206:198-206

31. Cheng TJ, Wong RH, Lin YP, et al. Chinese herbal medicine, sibship, and blood lead in children. Occup Environ Med 1998:55:573-6.

32. Koh HL, Woo SO. Chinese proprietary medicine in Singapore: regulatory control of toxic heavy metals and undeclared drugs. Drug Saf 2000:23:351-62.

33. Wu TN, Yang KC, Wang CM, et al. Lead poisoning caused by contaminated Cordyceps, a Chinese herbal medicine: two case reports. Sci Total Environ 1996;182:193-5

34. Ernst $\mathbf{E}$, Thompson Coon J. Heavy metals in traditional Chinese medicines: a systematic review. Clin Pharmacol Ther 2001;70:497-504.

35. Lee CH, Wang JD, Chen PC. Case-crossover study of hospitalization for acute hepatitis in Chinese herb users. J Gastroenterol Hepatol 2008;23:1549-55.

36. Chuang $\mathbf{C H}$, Doyle P, Wang JD, et al. Herbal medicines used during the first trimester and major congenital malformations: an analysis of data from a pregnancy cohort study. Drug Saf 2006;29:537-48.

37. Chung V, Wong E, Woo J, et al. Use of traditional Chinese medicine in the Hong Kong special administrative region of China. J Altern Complement Med 2007:13:361-7.

38. Chuang $\mathbf{C H}$, Hsieh WS, Guo YL, et al. Chinese herbal medicines used in pregnancy: a population-based survey in Taiwan. Pharmacoepidemiol Drug Saf 2007;16:464-8

39. Cui Y, Shu XO, Gao Y, et al. Use of complementary and alternative medicine by Chinese women with breast cancer. Breast Cancer Res Treat 2004:85:263-70. 